\title{
Introduction to the American Edition
}

The present book was written before the military coup d'etat that altered the Brazilian political scene during the last few days of March, 1964. To be more precise, it was prepared between October and December of the previous year, a critical period for the recent political evolution of Brazil. Toward the end of September the Goulart government had made an unsuccessful attempt to declare a state of emergency. This abortive attempt was evidence of the government's awareness of the gravity of the situation. On the other hand, the entire nation was conscious of the fact that the government did not possess the means for coping with a crisis that was daily becoming more acute. Thus a situation arose in which there was a void in power which foreshadowed a change in the conventional methods of political conduct. It was therefore natural that we should have asked ourselves what role should be assigned to the Left during the period of rapid transition through which we were living. It was enough simply to frame the question to realize the extent to which the forces battling for the modernization of Brazil had been overtaken by events. With the intention of promoting an intellectual mobilization of the Left, I wrote the present book, which did not claim to go beyond the formulation of a number of problems concerning which there was scope for a broad exchange of ideas. The heterogeneous nature of the 
book's contents is due to the diversity of the public to whom it was addressed, a public composed of persons with responsibilities or interests in the numerous political or quasi-political movements aiming toward transforming Brazil from a structurally anachronistic society into a modern nation. For this reason I thought it convenient to open the discussion simultaneously on the theoretical and practical planes. It was necessary to apply critical reasoning to current revolutionary dogmas if we wanted to go beyond the mere repetition of formulas and to exercise political imagination. On the other hand, it was necessary to proceed to an immediate examination of reality, since events were succeeding each other with disconcerting speed. As a matter of fact, this speed was even greater than we had imagined, and our intentions were completely frustrated.

Recent political events in Brazil, far from invalidating the analysis set out in Part Two of the present volume, have only served to confirm the theses there advanced. However, the reader who is unfamiliar with the Brazilian reality may experience some difficulty in attempting to fit the many elements presented in this part of the book into a pattern that would explain the recent aggravation of political instability. In order to facilitate this task, I have undertaken, in this Introduction, to present a broad survey designed to contribute to an understanding of recent events, which occupy a principal place in the minds of all those who concern themselves with the evolution of Brazil.

Brazilian economic development over the last three decades has been a typical case of industrialization directed toward substitution for imports. The expansion of coffee plantations that took place under the stimulus of the high prices prevailing in the late 'twenties led the country into an overproduction crisis at the very moment when the world market was becoming disorganized. Thus the country had simultaneously to face both the external crisis that obliged it to cut imports by half and an internal crisis provoked by the 
need to finance large surpluses of coffee production. In effect, there were years when the amount of coffee purchased for accumulation or destruction represented as much as 10 percent of the Gross Internal Product. The immediate aim of this policy was, of course, the defense of the coffee-growing interests.

Purchase of surplus coffee financed by expanding the means of payment tended to inflate the money income and to depreciate Brazilian currency abroad, which also favored the coffee growers and coffee merchants, since the price of this product went up in local currency although its international exchange rate was declining. This policy, however, had far wider consequences than were foreseen at the time. In effect, the rapid and persistent depreciation of the currency constituted a powerful protectionist barrier for domestic industry, which began to operate two or three shifts daily with the aid of small additional investments. The profits of the external sector declined, since official backing could only partially compensate for the drop in the real value of exports. Manufacturing production began to attract entrepreneurial capacity and financial resources on a growing scale. In this way, at the same time that the volume of foreign trade was reduced, productive capacity became more diversified. Between 1929 and 1937, while imports declined by 23 percent, industrial output rose by 50 percent.

The most recent phase of Brazilian industrialization is equally illustrative of the disparity between the political objectives aimed at and the results achieved. With a view to defending the international price of coffee, which was threatened by the large stocks still held in Brazil, the Brazilian government, immediately after World War II, followed a policy of external over-valuation of national currency. Experience had demonstrated that devaluation of the cruzeiro would have adverse repercussions on the international price of coffee, leading to a deterioration in the country's terms of trade. This policy, however, had the same effect as a lowering 
of the customs tariff, leaving national industry unprotected in the face of external competition. The strong protests of industrial interests were ignored, and the more powerful interests associated with foreign trade prevailed.

Once again, however, it was the indirect consequences, unforeseen by the policy-makers, that, in the long run, proved to be of the greatest significance. Exports rose rapidly while over-valuation of the currency was maintained, exhausting the reserves accumulated during the war and initiating the process of piling up external debt. Since coffee was the overriding consideration, and since a fall in coffee prices would have proved even more serious in view of the external debt, the government chose to introduce a system of controlling imports rather than devaluate the cruzeiro. This import control necessarily tended to favor the purchase of capital goods and other inputs in order to defend the level of existing industrial activity. Immediately below, in the scale of priorities, came the machinery destined to expand the capacity of existing industries. Thus, under the aegis of the defense of the external price of coffee, a twofold protection of industry was created: for all practical purposes, importing of "similar" products was prohibited, and exchange coverage was guaranteed for primary products, intermediary goods, and machinery at a subsidized rate. The government's firmness in maintaining this policy when the small coffee harvest of 1949 was announced was the cause of the sharp rise in the price of this product that took place in that year. On the other hand, the rise in coffee prices created the conditions that led the government to persist in its policy. In brief, as an indirect consequence of the policy of defending coffee prices, a substantial portion of the income created between 1949 and 1954 by the improvement in the terms of trade was transferred to the industrial sector by means of exchange subsidies.

The above observations make it clear that Brazilian industrialization was less the result of deliberate policy than the 
indirect consequence of measures taken to favor the interests of the traditional export economy. Unlike the classical type of industrialization, which got under way by creating its own market through the relative drop in prices which it promoted in markets previously supplied by craft industries, industrialization of a "substitution" type, like that which occurred in Brazil, takes place during a phase of rising prices of manufactured products, the result of a steep decline in the importation of these products.

The fact that industrialization occurred as a by-product of policies aimed at other objectives had various consequences. Thus, the effort to convert the substructure of an economy based on the export of primary products into an industrial system was not undertaken at the right time. The size of the country led to the creation of a constellation of regional economies linked to the foreign markets, but between the members of the constellation there was a limited mobility of production and little interchange. Industrialization had to be based on the integration of these semi-autonomous economies, which called for important investments of social capital by the Public Authority. On the other hand, obstacles to the import of "non-essential" products were raised without any compensatory measures. In this way, the less "essential" a product was, the more attractive investment in its production became, since such industries were relatively more protected from external competition.

The subsidy implicit in imports of machinery provoked further distortions, with even graver consequences to the process of capital formation. Thus, excessive imports of equipment, with an eye to future speculation, led to the formation of idle capacity in certain industries, reducing the efficiency of the economic system as a whole. On the other hand, a rise in the capital coefficient per worker was favored, a situation which tended to aggravate the crucial problem of any underdeveloped country, which is the existence of a structural surplus of manpower. 
Whatever may have been the characteristics of the industrialization process, there is no doubt that it entailed consequences for the country's social structure, with important repercussions on the institutions supporting the traditional power system. It would not be out of place to recall that the economic system and social structure of Brazil in 1930 had changed little from the century before. The country's economy continued to be based on the export of a number of tropical products, chiefly coffee, produced on the great estates, and the State continued to finance itself chiefly on the basis of taxes imposed on foreign trade. About four-fifths of the country's population lived on the large estates or was in one way or another subject to the direct authority of the great landowners. Only a small fraction of the population, about 1 percent, participated in the political process. The national state was vaguely identified by the mass of the population through some of its principal symbols. Local offices, even when these were integrated into the federal bureaucracy, were in the hands of the landowners, who held control of the municipal and state governments. In short, those who were in power possessed all the means to keep themselves in power.

Stagnation in the export agricultural sector, concentration of investments in manufacturing activities, and finally the growth of state activities have brought about important changes in the country's social structure over the last three decades. The principal manifestation of change was a process of rapid urbanization. In effect, the Brazilian population, which in 1920 was about 30 million, with about 7 million living in the cities, is today more than 80 million, of whom more than 35 million are concentrated in urban areas, with a much greater proportional growth in medium and large cities. As the urban population represents a much higher coefficient of literacy than the rural, it is natural that political activity should have undergone an important shift in its center of gravity, at least insofar as the electoral process is concerned. 
These changes in the social structure did not, however, find any adequate correspondence in the framework of political institutions. The lack of an industrial class, whose position had been defined in terms of a conflict of interests with the basic interests of the former ruling groups, hindered the emergence of a new leadership who could promote the modernization of the institutional framework. Many causes can be found to which to attribute this lack of renewal in Brazilian political leadership, during a period when such important changes were taking place in the country's social structure. I shall draw attention only to the fact that industrialization which begins late in the present century has to create a considerable geographical concentration, in view of the importance of external economies, the need to operate on a basis of large units, the concentration of supplementary services, such as power supply and transport facilities, and so on. Thus, the São Paulo region came to represent an increasing proportion of Brazilian industrial output, and at present contributes approximately 40 percent of this output. This geographical concentration of industrial activity, in a country with a power structure organized on a federal basis, necessarily tends to reduce the political importance of the industrial sector. This circumstance, coupled with the fact that many industrialists also had agricultural interests, contributed toward continuing control of the principal centers of political decision by the leadership connected with the traditional economy.

To the lack of influence on political leadership by the industrial class must be attributed, to a large extent, the slow modernization of the political institutional framework in Brazil. Political constitutions, including the latest (established in 1946), have been a powerful instrument in the hands of the traditionalist oligarchy for preserving its position as the principal political force. The present federal system, in providing considerable power for the Senate, in which the small agricultural states of the most backward areas have a decisive 
influence, places the legislative power under the control of a minority of the population living in areas where the interests of the great estates hold undisputed sway. On the other hand, as representation of the individual states in the Chamber is proportional to population, illiterates are represented by literate fellow-citizens. Thus, the vote of a citizen living in a State where 80 percent of the population is illiterate is worth five times as much as the vote of a citizen living in a state with one hundred percent literacy. Since the traditional oligarchy is most powerful in the most illiterate areas, the electoral system contributes toward the maintenance of this oligarchy, which finds in illiteracy one of its props. This fact is not without bearing on the strong reaction shown by many local authorities in the more backward regions against the introduction of techniques for simplifying the spread of literacy.

Control of the principal centers of a power system is not a sufficient reason, however, for the majority of the population to accept as legitimate the authority emanating from this control. And it is because this legitimacy has been increasingly lacking in Brazil that the exercise of power by the ruling class has become increasingly difficult. In effect, the relative growth of the urban electorate has offered a permanent challenge to the control of the electoral system by the parties based on the oligarchy. Experience has already shown that, if the creation of new parties is possible, a movement based on the urban centers can decide the results of a major election. In fact, elections of the President of the Republic and State Governors in the more urbanized states have been increasingly influenced by forces that evade control by the oligarchy. Thus conditions had arisen in which the Executive Power represented emergent political forces that defied the control of the Establishment, which concentrates its forces in Congress. Tensions between the two power centers had increased over the last fifteen years, and had on occasion even led to hindrance of government action. ${ }^{1}$

Changes in the Brazilian political process must be analyzed 
in the light of the modifications that have taken place in the country's social structure and particularly in the characteristics of its urbanization process. Unlike the classical case observable in Europe during the last century, in which urbanization expressed a rapid change in the occupational structure, for most of the industrial working class in Brazil urbanization has been much more complex. Brazilian industrialization was not accompanied by disorganization of the craft industries, and consequently the first-generation industrial worker was not conscious of having suffered any social degradation. On the contrary, having emerged from conditions similar to those of a rural serf, the worker was aware of having risen in the social scale. However, industrialization was only one of the factors responsible for urbanization. In actual fact, during the decade between 1950 and 1960, while industrial output grew at an annual rate close to 10 percent, employment in industry increased at a rate of 2.8 percent, or approximately half the rate of urban population growth. Increased public expenditure, with a heavy concentration of income creating an expanding market for services, is another factor responsible for the creation of urban employment.

The urbanization process does not constitute, however, a simple reflection of the changes in the country's occupational structure. The underemployed population living in urban areas has actually increased at an even greater speed than the number of people effectively employed in industries and services. This is a phenomenon that is not easy to explain if the country's present agricultural structure is not taken into account. The agricultural pattern that predominates throughout the country, based on rudimentary techniques, has been increasing its costs as a result of the natural exhaustion of soils and the moving of farms further inland from the principal consumption centers along the coast. According to the 1960 census, more than 90 percent of Brazilian agricultural land was situated on medium and large estates utilizing no more than 8 percent of this land for crops. While extreme under- 
utilization of land continues, as a result of the way in which agriculture is organized, the expansion of the land under cultivation has been dependent to a large extent on multiplying the small estates, whose average size has decreased between 1950 and 1960, according to agricultural census figures for these years. Bearing in mind that this decrease in the average area of the small holding is coupled with soil exhaustion and increased distances from consumption centers, it is not surprising that the standard of living for a great part of the rural population has decreased. This population tends to move to another agricultural region to try to find some form of occupation. From this inter-rural migratory process a growing proportion of the population tends to filter into the urban areas, where even the most precarious livelihood seems attractive compared to the insecurity and extreme poverty of life on the land. In this way, in all Brazilian cities, medium and large, great masses of the underemployed begin to congregate, occasionally being employed in public works, building sites, and unstable jobs in services.

Together with the working class, who are of declining relative numerical importance, and the mass of the underemployed, who are of growing relative importance, the urban population is made up of a substantial and growing contingent of the "middle classes." Here, too, the simple transposition of concepts derived from different historical experiences must be avoided. The middle classes of the classical European model were marked by the presence of the "petit bourgeoisie," who were self-employed and motivated by a strong individualistic spirit, the basis of the Liberal ideology. The present Brazilian middle class is basically made up of white-collar workers, earning medium and high salaries, who work in the numerous government organizations, private banks, offices of industrial and commercial firms, and the various forms of services concentrated in big cities. This middle class is the backbone of the organs of state at their administrative level, the organs of communication, and the cultural 
institutions. Because they influence movements of opinion and interfere in the organs of decision, these middle-class groups have managed to acquire a series of privileges that range from control of agricultural prices to free higher education for their children. Although intellectually inclined toward the idea of development, and often adopting Leftist positions, the middle classes undoubtedly constitute a privileged group within the present system of income distribution.

This heterogeneous urban population, in which a privileged middle class exists side by side with a growing mass of the underemployed, had become the new decisive factor in Brazilian political struggles. Unlike the happenings in Europe in the last century, where social struggles assumed an increasingly defined form as a conflict between groups with growing class consciousness, which permitted the expression of these conflicts in terms of a political dialogue based on the confrontation of economic interests, in Brazil social tensions express states of dissatisfaction among a growing urban mass difficult to characterize. This amorphous mass is what constitutes the basis for the Populist movements that characterize Brazilian political struggles in recent decades.

In view of this rupture in the basis of the power system, the very principle of legitimacy has been seriously compromised. In order to make itself legitimate, the government must act within the framework of constitutional principles and at the same time fulfill the expectations of the majority responsible for its election. However, in attempting to carry out the substantive mandate of the masses who elected him, the President of the Republic necessarily came into conflict with Congress, and was faced with the alternative of betraying his program or forcing an unconventional way out. In ten years this unconventional way out has included one suicide, one resignation, and one violent deposition. It could be argued that the Presidential candidate could offer a realistic program, taking into account the power of those who control both Congress and a considerable part of the state apparatus. 
But this moderate candidate would find it difficult to get himself elected, since another candidate would readily be forthcoming who was prepared to come to terms with the demands of the masses.

The emergence of a mass society, paving the way for Populism, without the formation of new ruling groups able to work out a plan for national development as an alternative to the traditionalist ideology, has been the chief characteristic of the Brazilian historical process in its most recent phase. The Populist leaders, conscious of the psychological state of the masses, called for the country's rapid modernization through "basic reforms" and "structural changes." Control of the principal political power centers, however, continued to be in the hands of the traditional ruling class, who have known how to use Populist pressure as a bogey for bringing to heel the new emergent forces connected with industry and foreign capital. These circumstances, responsible for the growing political instability, favored military intervention and indeed this did in effect take place in March, 1964. The intervention, however, did not eliminate the roots of conflict but only fostered in the old ruling class the illusion of an entrenched security. Now, unless development as a basic aspiration for the Brazilian community is successfully suppressed, social pressures will continue to grow if changes are not introduced into the social structure, and the profundity of these changes will have to increase with the passage of time. A society that shows itself incapable of creating a ruling class equipped to guide its process of change is not necessarily a society that tends to remain stagnant. Nevertheless, there is a high probability that the social cost of such change will increase, if particular historical conditions permit a strengthening of the forces opposed to social change.

Yale University

C. F. June, 1965 